\title{
A New Scholarship of Classroom-based, Open, Communal Inquiry
}

\section{ABSTRACT}

This article argues that SoTL may draw on and inform other scholarships-of discovery, application and integration-by bringing them into a classroom- and community-based scholarship of communal inquiry. In so doing, SoTL will resist teaching being regarded and evaluated as transmission and delivery of knowledge made elsewhere, reasserting the classroom as the place for the development of knowledge- and meaning-making, the site and focus of 'teaching-led research'.

It outlines a scholarship of communal inquiry which includes students, community and academics, as well as 'Discovery' and Teaching and Learning scholars: a boundary-crossing community creating, evaluating and publishing disciplinary knowledge, including from open data and curriculum- and assessment-change processes.

Further, that a scholarship of inquiry that is developed in partnership with community interest groups (through scholarship of application projects), grounding and re-valuing the research agenda of higher institutes and professions while reimaging the curriculum, will prepare the student to become that lifelong, practitioner-scholar so needed for our future.

\section{KEY WORDS:}

teaching-led research, disciplinary scholarship, community engagement, liberal education, open science, practitioner-scholar, Boyer

\section{FROM DEPRESSION TO DREAM: AN ISSOTL CONVERSATION}

At ISSOTL 10, one keynote speaker broke the news that the UK government had just announced a fundamental change to the funding of UK university teaching. We, an international group of long-term ISSOTL friends, huddled together, shocked at this demonstration of the instability of our academic terms and conditions, and tried to absorb what it meant to us as scholars. We realised that in this time of rapidly changing agendas and institutional frameworks worldwide, we needed our SoTL communities as never before; that SoTL was the linchpin in our work as discipline academics. And, as always at ISSOTL, we started to envision what we could do to turn this new manifestation of 'the university in ruins' to account.

What seemed catastrophic in the news-of the non-funding in the UK of the HE 
teaching of non-STEM (Science, Technology, Engineering and Maths) subjects-was the brutal division of university teachers into 'useful' and 'useless'. Not a new division, but stark in its effects. What then were the goals, agendas and point of non-professional university curricula? By proposing a new Scholarship of Communal Inquiry, I hope to 'flag up' an answer to that question: with the goal of qualifying the student, through knowledge- and meaning-making activities in the classroom, as a lifelong member of a community of open scholarly practice.

This news seemed to change the outlook for all UK university teachers, privileging some areas of knowledge creation as productive and others as to be funded only by 'consumers' paying 'real costs of the provision'. It seemed to strike another blow at the idea of the 'university' as universal and a place of liberal education rather than skills and training provision, and to erect yet another division between teachers. But, we realised that at this time of rapid and often disturbing structural change in higher education worldwide we have to centre ourselves in classroom practices, classrooms that must provide the base for knowledge- and meaning-making that draw on and validate disparate and divided modes and sites of intellectual work.

I propose here an answering vision of a SoTL-based Scholarship of Communal Inquiry, and of us teachers as members of inclusive communities of inquiry-based practice; of teaching and learning inquiry which breaks down barriers, especially between teaching and research; pure and applied, hard and soft, useful and 'useless' disciplines; Faculty, students, and the wider learning community and joins up the students' learning at university with their later life. But, conversely, in an age of democratised, unregulated open science (Peters, 2012), open publishing, academic blogging, tweets from all over the world flashed up behind keynotes ... it seeks to re-establish the university classroom as the primary site, and gatekeeper, of disciplined, scholarly knowledge-creation.

\section{THE NEED FOR A NEW, SOTL-BASED, UNIFYING, OPEN SCHOLARSHIP OF COMMUNAL INQUIRY}

I imagine here a SoTL-based, boundary-crossing community drawing on and informing knowledge-making by students and teachers, in research and teaching institutions, in universities and their communities, in undergraduate campuses and beyond. SoTL, as concerned with improving student learning, will be central in validating such unifying knowledge-making practices, since the core of such a community will be, can only be, the university classroom.

Such a scholarship is urgently needed because of the fragmentation of knowledge in a deregulated open knowledge economy and the loss of confidence in universities' place, mission, and usefulness: and so loss of confidence also in our place, mission and usefulness as teachers. In the US and Europe there has been recent and high profile investment in Open Science, a web of knowledge outside academia, where academic review, if it happens at all, happens long after the instant publication of findings (for some implications see Peters, 2012). This goes with a concern over the viability of university liberal arts courses. Pressure on income from endowments and on new investments in tough economic times brings questions from donors and parents alike about the worth of university qualifications which do not lead directly to a vocational or professional career or scientific research post. Economic crises make central governments demand more economic bang for their educational buck, exacerbating the divides. Pressure mounts on 
SoTL to promote effective transmissive rather than transformational teaching methods, of interest to academic development rather than disciplinary academics. Transmissive pedagogy is most usefully adopted and adapted for qualifying courses where the knowledge and understanding achieved must be validated and accredited by external professional bodies but elsewhere undermines creativity, liberal arts knowledge-making and 'new epistemologies' (while industry and business leaders stress their need for creativity and new thinking and STEM subjects themselves look to creative, humanistic methods of inquiry (see Council for Industry and Higher Education at http://www.cihe.co.uk /category/themes/key/skills/).

Given that we have been working for many years with the discourse of skills, performance, consumers and marketing — of transferable and employability skills and learning outcomes, of curricula aligned to vocational and professional accrediting bodies-our ISSOTL10 reaction of shock may sound naïve and parochial: the result of unrealistic nostalgia. Perhaps; but the newly prevalent policy of treating university undergraduate teachers as disseminators, providers of and trainers in others' knowledge seems to strike at the heart of SoTL. For, in locking us teachers into a system of provision rather than liberal and liberating education, it simultaneously locks scholars of teaching into a system of scholarship of delivery rather than creation — creation of understanding and meaning - in our classrooms. By so doing, it reasserts scholarship of (pure and applied hard) discovery as the master and scholarship of teaching as the servant, tasked with delivering the knowledge discovered by the master and judged valuable by the state. We felt strongly that such disconnect was a disservice to all academics; it jolted us into thinking about ourselves as scholars and considering whether now is the time for SoTL to look for potential mutual benefits in developing and synthesising aspects of all four scholarships.

\section{CONNECTING THE SCHOLARSHIPS}

Boyer wrote of the link between the 'other three' scholarships: the 'absolutely crucial', enlivening and invigorating Discovery; the needful, meaning- and perspective-making Integration - and quoting Van Doren : "The connectedness of things is what the educator contemplates to the limit of his capacity...”. He concludes Application, in which 'theory and practice vitally interact, and one renews the other, with what I now see as a 'call to arms' for all those involved in SoTL:

Such a view of scholarly service-one that both applies and contributes to human knowledge - is particularly needed in a world in which huge, almost intractable problems call for the skills and insights only the academy can provide. (Boyer, 1990: 18-19, 22-3 23)

Despite the many attempts to divide us as teachers from researchers, it is important to call for SoTL to resist divisions between institutions which create and those which disseminate higher level knowledge, and to help us recapture the sense of our classroomseach and every, gen. ed. and writing intensive, major and minor-as hot spots of creative, transformative disciplinary epistemological practices.

We must look to SoTL for models of knowledge created as well as mediated at the undergraduate university and to use those models to generate inclusive new knowledgecreating, -validating and-disseminating scholarly communities. For the development of knowledge cannot now, if it ever could, be left to research silos, staffed by non-teaching 
research stars, but must, rather, be driven by disciplinary processes 'in action' in (and after) the university classroom.

So, at the start of this important new venture-Teaching and Learning Inquiry-I want to look again at the relationship between the scholarships, to argue that we need to re-embed SoTL in the other three scholarships in a process that should enhance and illuminate SoTL and-now here I wish to be evangelical—just possibly save Liberal Arts university education.

\section{SOTL AND TEACHING-LED RESEARCH}

I like to imagine SoTL as a community not just of scholars of teaching but also of teaching-led research: which means the research community-and indeed all academicstaking on agendas, problematics and results from classroom knowledge-making and knowledge-questioning practices. This would be an inclusive teaching-led research community, joining 'research' and 'teaching' universities, R1s and community colleges, distance institutions and ivy-clad, ivory-towered campuses. Lee Shulman (2011) in 'The Scholarship of Teaching and Learning: A Personal Account and Reflection' makes an important distinction between Boyer's four scholarships and the Carnegie Foundation that led to the Carnegie Academy for Scholarship of Teaching and Learning. For whereas

Boyer was making the necessary argument that the work of the teacher needed to be valued in the Academy in a manner comparable to the work of a researcher, we wished to go even further... while engaging in excellent teaching was indeed a scholarly act, until college and university teaching were quite literally acts of scholarship it was somewhat ingenuous to claim that they were equivalent

Although all of us who worked in disciplinary scholarship welcomed the validation of our teaching that Scholarship of Teaching and Learning gives, Shulman's 'going further' increases demands on academics, if they are to be not only excellent, scholarly or expert teachers but also scholars of teaching (Kreber's distinction, 2002). And there is the danger that SoTL's institutionalisation could encourage the separation of the scholarships which Boyer seminally related. For in the urging of parity of esteem and career track for SoTL and the demand for publication similar yet distinct from that of [disciplinary] research, and in leaving out of account work on scholarships of application and integration, it has tended to isolate our teaching and ourselves as teachers; to create silos at both the individual and institutional level. A SoTL-based scholarship of inquiry asks all academics to develop, reflect on and disseminate in a fully scholarly way their discipline-inpractice: the processes of discipline inquiry from the classroom and in application and integration, to illuminate and inform the research agenda.

\section{THE SCHOLARSHIPS OF APPLICATION AND INTEGRATION IN THE INQUIRING CURRICULUM}

The curriculum of communal inquiry proposed here looks to disciplinary developmentdisciplinary identity and ontology as well as epistemology-drawing on all the scholarships to do so. It would be for us in SoTL to ensure that disciplinary research skills and undergraduate involvement in research are properly embedded in the curriculum; that 'application/engagement' projects avoid Boyer's harsh strictures that: 
all too frequently, service means not doing scholarship but doing good. To be considered scholarship, service activities must be tied directly to one's special field of knowledge.

At the same time, they must meet his transformative aim:

Such a view of scholarly service-one that both applies and contributes to human knowledge - is particularly needed in a world in which huge, almost intractable problems call for the skills and insights only the academy can provide.

I am suggesting that Scholarship of Application aspects be built into a curriculum under the direction of scholarly disciplinary teachers reporting into and blurring the boundaries of both their communities of practice, those of SoTL and of disciplinary research/discovery.

Similarly, that it is for SoTL to investigate and develop coherent curricula promoting integrated learning; a revitalised, reconnected scholarship of integration which would meet and build on the Association of American Colleges and Universities aspirations. AAC\&U's 2002 Greater Expectations recognized the urgent need for a new vision of higher education for the twenty-first century, and urged the adoption of a reinvigorated liberal education in which colleges and universities 'model the purposeful action - the intentionality-they expect of their students' through the provision of an education that 'requires integrating elements of the curriculum traditionally treated as separate-general education, the major, and electives - into a coherent program' (AAC\&U, 2002: xiii). And take further the AAC\&U and the Carnegie Foundation's initiative 'Integrative Learning: Opportunities to Connect' (Carnegie Foundation for the Advancement of Teaching, 2006).

Such a re-connecting of integrative learning initiatives with SoTL scholarship would refocus the scholarship of integration on knowledge-making activities, argued by Alan Booth to be vital yet overshadowed in the emphasis on personal skills, experience and development in extra-curricular projects (Booth, 2011). A Scholarship of Inquiry would look to, evaluate and indeed integrate both epistemological and pedagogic objectives in integrated learning projects in the classroom.

\section{WHAT WOULD AN INCLUSIVE, TEACHING-LED SCHOLARSHIP OF COMMUNAL INQUIRY LOOK LIKE?}

Since that ISSOTL conversation, I have continued to imagine what such an inclusive, teaching-led scholarship of communal inquiry might be like in practice; a scholarship of teaching and learning in the classroom, responsible for and enabling a reaching out from there into research institutions, into the community, and into the later lives of current students. Envisaged here are scholarly communities of practice for all university teachers, in which undergraduate curricula are designed to integrate scholarly activities - of discovery, integration and application-within a paradigm of creative, inclusive, nondelivery-oriented scholarship of teaching and learning.

Such scholarly communities would not change or dilute the attainments of or demands on scholarly or expert teachers or of scholars of teaching, but the central focus of SoTL would be on classroom-based, scholarly knowledge-making: disciplines-in-practice. The audience for this SoTL work would be fourfold-fellow scholarly and expert teachers; 
scholars of discovery (disciplinary researchers, research bodies and funders); scholars of application (ensuring that both scholarship and application are properly centred on, as Boyer put it, not only doing good but doing scholarship in one's field) and on scholars of integration-currently perhaps the most under developed of the scholarships. This would ensure that the integration projects in the classroom inform and are informed by productive new epistemological models of the discipline-in-action.

Fellow SoTL scholars can better imagine how to realise some of these aspirations: especially perhaps those in ISSOTL subject interest groups such as Sociology, Humanities, History, Science, Geography, or Earth or Environmental Sciences/Studies. The case is urgent for non-STEM teachers, but we all are concerned with and concerned about the potential model of an international league table of STEM-only research university institutes; scientists have also expressed concern about the loss of creativity and blue skies questioning involved in separating science research (Petsko, 2010, splendidly so) and all are challenged by the deregulated Open Science Economy. We Humanists are concerned not only for our and our students' futures but because we have for some years been gaining ground in arguing for the richness of arts and humanities' methodologies, hermeneutics, inter-cultural capacity building, creative problematizing and paradigm-enriching potential for collaborative inter-disciplinary projects and universities as a whole (e.g. Haynie, Chick and Gurung, 2012; Pace, 2007; Parker 2007; 2008; Belfiore and Upchurch, 2013).

The first boundary for 'Communal Inquiry' to cross would be that between Faculty and students: we could highlight SoTL networks like Student Engagement, Students as Co-Inquirers and Advancing Undergraduate Research and the Council for Undergraduate Research, which opens ISSOTL conferences, to promote and promulgate a new kind of classroom-based research community, involving the most senior of research academics in co-inquiry with the newest fresh-man and -woman. In its way this bringing of the research community to the classroom might be as radical as the Writing in the Disciplines movement, which suggested that all the disciplinary community's writers, from fresh [wo] man to Regius and Endowed Professor, write the discipline. For as Monroe's book, Writing and Revising the Disciplines shows (2002), to write is to revise the discipline, and by including all in writing they are involving all in remaking the discipline's knowledge base and epistemological agenda. Such a model of a classroom-based, inclusive community of disciplinary inquiry, of meaning-making and agenda setting, would inflect our undergraduate curriculum from start to graduation.

\section{CURRICULUM SHAPE AND ACTIVITIES}

An empowering disciplinary communal scholarship, embracing and fructifying inquiry/research, application/engagement and integration, is a little difficult to envisage; ISSOTL disciplinary interest groups could help better to fill out the picture.

Yet, the curriculum might start with new students being introduced into a working community, perhaps, like one material science department, with an open-door induction week when students interview each researcher and be informed about all knowledgemaking processes, to generate an immediate sense of inclusion and an alive sense of what inquiry, engagement and integration in that discipline means. An English Literature department could encourage students to ask questions, review recent books and articles with their authors, make an overview of upcoming symposia and community events to 
give the new student a sense of the sheer plurality of disciplinary framings, of modes of knowledge-making and of the multiple and potentially contested narrating of and plural audiences for disciplinary processes and experiences. Disciplinary content is essential, but this start signals that any content is framed and addressed in particular and various ways and is the result of epistemological processes. It signals equally that performing and presenting disciplinary research varies according to the space and audience of different interest groups within and without the university-interest groups that may test, develop and root disciplinary identity.

One area for immediate SoTL development, rooted like SoTL in practitioner action research, could be the exploration of disciplinary writing: mobile, multiply addressed and newly questioning genres of writing concerned with knowledge- and meaning-making and with transforming the disciplinary paradigm. Whereas Academic Literacies research, undertaken by literacies and discourse analysts, is concerned with making transparent and achievable institutional rubrics (following Lillis' seminal Student Writing: Access, Regulation, Desire, 2001), Scholars of Teaching and Learning can, rather, follow Writing in the Disciplines-which insisted that all the disciplinary community's writers write the discipline-and develop new forms of disciplinary writing. A classroom-based community of discourse should have various modes in which to express and develop disciplinary identity, voice and values, rather than taking 'top-down' models from disciplinary research writing. Our inquiry-based SoTL community could advise on the developing and evaluating of appropriate participant-observer narratives and of action research projects reports. It could also foster their dissemination, using www 2.0 technologies and the genre of self-narration of experience, as in the mode of autoethnography (critiqued in Anderson [2006] and developed in such publications as Life Writing).

Whereas most curricula are imaged as pyramidical, moving from wide basic content and skills acquisition courses to higher order thinking and specialism, one could envisage an 'inquiry curriculum' as the reverse: developing Medical Education's adaptation of Bruner's spiral curriculum, one which spirals up and out from narrow knowledge acquisition to wider reflection, application and integration of domain and inter-domain knowledge (Harden and Stamper, 1999). Such a curriculum breaks the hard/soft and pure/ applied boundaries by inquiring, applying and engaging all kinds of knowledge making, which is why it leads the medical trainee from 'pure' to 'applied' medical science and to knowledgeable, reflective medical practice.

This spiral, integrative curriculum would include weekly sessions, perhaps at domain rather than discipline level, on meta-level questions about values, about different forms of inquiry, about various contextualisings and various possible narrations of disciplinary experiences and research. For just as questions about medical ethics and about models of health and illness are brought into the medical curriculum from the start, because the responsibility for developing and embodying best practice is incumbent on the whole medical community, so should disciplinary knowledge-making practices, values and agenda be openly discussed and negotiated from week one.

I emphasise the medical practitioner curriculum model because the change I am trying to describe is one of qualifying the undergraduate to become a practitioner-scholar: in their discipline, with senior academics; in their communities, with interest groups, and in their later, working life. The discipline could from the start include students in 
engaging with various outside interest groups, negotiating their multiple discourses and differently inflected agendas. Such a curriculum, bringing together discovery and teaching scholarship, would draw on and engage the community outside that the student will eventually serve and/or join; the vital objective is that during their undergraduate time students develop disciplinary skills, knowledge and understanding as a baseline for future practice, as part of an ongoing community of inquiry, whether they then stay within an academic context or not. Such a community of inquiry involves all concerned in the discipline in supporting the students' development of an autonomous disciplinary voice and the start of a disciplinary identity. (SoTL work on Transitions, on Induction and on Inclusion is vital and pertinent here.)

Methods of inquiry and Work in Progress sessions, involving new forms of writing, would run throughout the degree programme (see exemplary existing examples of student scholarly communities, such as the University of Glasgow's e-Sharp, an international online journal for postgraduate research; run entirely by graduate students, it aims to provide a critical but supportive entry into the realm of academic peer-reviewed publishing for emerging academics. The culmination of such a degree could perhaps include a festival — of presentations, performances, projects and ideas-in-progress (such as those of creative and performing arts degrees).

\section{From classroom to community, from student to practitioner}

What students would have on completion would be a portfolio of completed work, several years experience of working and writing with and for a disciplinary community, and a clear sense of what work the discipline could and should be concerned with in the world as well as in academia. The disciplinary identity inculcated may be comparable with that in anthropology, where the new anthropologist is prepared to go into a hitherto unexplored culture, not knowing what she will find or how to tackle the questions that come up immediately, but with an armoury of different ways of approaching, unpacking and narrating the significance of what she encounters. So all Humanists, Cultural and Social Studies graduates should be equipped with all kinds of investigative, interrogatory and dialectical methods and modes of ethnographic writing (see, e.g., Clifford and Markus' seminal Writing Culture: The Poetics and Politics of Ethnography, 1986).

These graduates would be familiar with a range of research methods and practices: such as how to find and access textual resources of all kinds, obviously, but also the selective use of networks, social referencing sites, e-journals, wikis, blogs, conference sites and electronic lists with which to keep in touch. Moreover, as we move into an 'open science', deregulated publication era, they could have a vital role in bringing into the academic community the results of such open research. For members of the community of inquiry proposed here are best placed to police the bounds of the discipline, using social media and social referencing academically and bringing into academia significant reflections and crowd-sourced observations.

The model proposed here would mean incorporating aims and outcomes in undergraduate programmes similar to those that many applied subjects are used to including, as they prepare undergraduates to enter into their chosen field with a portfolio of work (in design, photography, fashion, creative writing, engineering etc). More innovatory would be the evidence of a 'real world' project completed. This would both draw on and embed within the university models of scholarship of application, just as it draws on and embeds 
in the undergraduate curriculum the scholarship of discovery; integrating scholars into our SoTL-led scholarship of communal inquiry.

\section{Towards Life-long Scholars of Communal Inquiry}

It is this bringing together of all the scholarships-SoTL, Discovery, Application and Integration - in a curriculum of communal inquiry that would equip students to carry on working in their discipline, in some way, after leaving the university: exit from the undergraduate university need not be an exit from the research community.

The effects on the structures of the research community that make up the scholarship of discovery would be profound. Like many of my colleagues, I have until now envisaged graduate study as the start of research training, and the $\mathrm{PhD}$ as the basic qualification for entering the discipline as an autonomous researcher and future teacher. The aim of undergraduate programmes has been to inculcate many disciplinary 'habits of mind' and to prepare those entering immediately into the world of work-leaving the universitywith 'graduate capacities' and 'graduate attributes'. The curriculum of communal inquiry proposed here could bring about a radical change, away from seeing disciplinary research cultures as almost entirely within academia. Rather, it gives Faculty three years to give students the capacity to continue to develop themselves and, indeed, the discipline, in research areas which may be informed by the working of the disciplinary interests in society generally. It envisages the curriculum as permeable and permeating and as comprehending inquiry, application and integration projects; it envisages SoTL as reviewing and reimagining models of learning and curriculum.

But most important is the input of university Faculty members into promoting their community's research publication. Rigorously reviewed e-journals, newsletters, blogs, would all contribute to a Writing in the Disciplines community encouraging the variety of disciplinary writing proper to a vibrant discipline (Monroe, 2002, 2003). The modes of writing would be various: multimodal, reflective, review articles, contextualised case studies, 'thought' pieces about the methods, practices and interests of the discipline outside academia ... (History SoTL - the International Society for the Scholarship of Teaching and Learning in History [http://www.indiana.edu/ histsotl/blog/]) —is considering including open scholarship of all kinds from all sources. In a deregulated world, the new scholarly community of inquiry would be charged with modelling the evaluation and validation of open data.

\section{The ongoing, overarching role for Scholarship of Teaching and Learning}

Where does this leave Scholarship of Teaching? My answer is, in a newly central place. For rather than SoTL providing the techniques to investigate and validate effective research-led teaching, this New Scholarship of Communal Inquiry promotes, evaluates and disseminates knowledge made in the classroom and by the consequent ongoing learning community. That is to say, rather than teaching being a process of mediating knowledge created elsewhere, the change of focus is to a model of teaching-led research.

The re-centering of knowledge-making in the undergraduate curriculum, the obligation to reach out and engage the wider community and to create and maintain an ongoing community of inquiring practice, to police and selectively bring into the community deregulated open research, may seem to put even more pressure on members of 
ISSOTL, given our essential obligation to investigate, evaluate and publish teaching and learning interventions and change. But I hope that what might seem an extra level of demand might, as well, be an extra validation.

Jan Parker researches and teaches Comparative Literature in the University of Cambridge's Faculties of Classics and English and she is Chair of the Open University's Humanities Higher Education International Research Group.

\section{REFERENCES}

AAC\&U. (2002). College learning for the new Global Century. Washington, DC: Association of American Colleges and Universities.

Anderson, L. (2006). Analytic autoethnography. Journal of Contemporary Ethnography 35(4), 373-395.

Belfiore. E., \& Upchurch, A. (Eds). (forthcoming, 2013) Humanities in the twenty-first century: Beyond utility and markets. London and New York: Palgrave.

Booth, A. (2011). 'Wide-awake learning': Integrative learning and humanities education. Arts and Humanities in Higher Education, 10(1), 47-65.

Boyer, E. (1990). Scholarship reconsidered: Priorities of the professoriate. Princeton, NJ: Carnegie Foundation for the Advancement of Teaching.

Carnegie Foundation for the Advancement of Teaching (2006). Integrative learning: Opportunities to connect.. http://www.carnegiefoundation.org/elibrary/integrativelearning

Clifford, G., \& Markus, J. (1986) Writing culture: The poetics and politics of ethnography. Berkeley and Los Angeles CA: University of California Press

Council for Industry and Higher Education. http://www.cihe.co.uk/category/themes/key /skills/.

Harden, R., \& Stamper, N. (1999). What is a spiral curriculum? Medical Teacher, 21(2), 141-143.

Haynie, A., Chick, N. and Gurung, R.A.R. (2012). From generic to signature pedagogies: Teaching disciplinary understandings. In Chick, N., A. Haynie, \& R.A.R. Gurung. (Eds.) Exploring more signature pedagogies: Approaches to teaching disciplinary habits of mind, (pp. 1-18). Sterling, VA: Stylus.

Kreber, C. (2002). Teaching excellence, teaching expertise, and the scholarship of teaching. Innovative Higher Education, 27(1), 5-23.

Lillis, T. (2001). Student writing: Access, regulation, desire. London: Routledge.

Monroe J. (2002) Writing and revising the disciplines. Ithaca NY: Cornell University Press.

Monroe J. (2003) Local knowledges, local practices: Writing in the disciplines at Cornell. Pittsburgh PA: University of Pittsburgh Press.

Pace, D. (2007). The internationalization of History teaching through the Scholarship of Teaching and Learning: Creating institutions to unite the efforts of a discipline. Arts and Humanities in Higher Education, 6(3), 329-335.

Parker, J. (2007). Future priorities of the Humanities in Europe: Working papers for the EC Working Party. Arts and Humanities in Higher Education, 6(1), 123-127. 
Parker, J. (2008). What have the Humanities to offer 21st-century Europe? Arts and Humanities in Higher Education, 7(1), 83-96.

Peters, M. (2012). Open Science economy: Creativity, collaboration \& the commons. www .srhe.ac.uk/downloads/events/54_M_Peter_ppt.pptx.

Petsko, G. (2010). A Faustian bargain. http://genomebiology.com/2010/11/10/138

Shulman, L.S. (2011). The Scholarship of Teaching and Learning: A personal account and reflection. International Journal for the Scholarship of Teaching and Learning, 5(1), 1-6. http://www .georgiasouthern.edu/ijsotl. 